\title{
COESÃO TEXTUAL: O ARTICULADOR "ONDE"
}

\author{
Janice Helena Chaves Marinho \\ Universidade Federal de Minas Gerais
}

\section{Introdução}

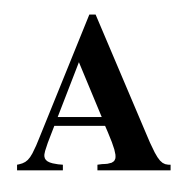

língua, aqui concebida como "uma atividade, uma forma de ação que se manifesta em toda sua amplitude no texto", ${ }^{1}$ possui recursos que, atuando na estrutura de superfície, ou seja, na estrutura morfofonológica, sintática e lexical de sentenças de um discurso, têm por função proporcionar o estabelecimento das relações textuais. Tais recursos podem ser vistos como "pistas" expressas no texto que possibilitam a produção de sentidos por ocasião do processamento textual.

Ordem de palavras e ordem de sentenças, uso de conectivos, advérbios sentenciais, tempos verbais ou pronomes são exemplos desses elementos, expressões da estrutura de superfície da coerência semântica de um discurso (van Dijk, 1996). ${ }^{2}$

Neste trabalho, pretendo apresentar uma análise preliminar da atuação de um mecanismo - o item onde - aplicado à sentença e ao discurso, e discutir as minhas interpretações dos usos que se têm feito desse item em textos orais e escritos, produzidos por alunos e professores universitários.

Foram extraídos dos textos pesquisados exemplos de usos do onde que parecem apontar para uma ampliação no seu campo de

\footnotetext{
${ }^{1}$ CASTILHO, 1998, p. 56

${ }^{2}$ VAN DIJK, 1996, p. 42
} 
atuação. Encontraram-se casos em que o onde atua como advérbio relativo aplicado à sentença, retomando um antecedente expresso, indicando o lugar físico ou "nocional" em que se situa uma ação verbal, ou ainda a noção de tempo e de posse. Encontraram-se, também, exemplos em que ele parece se aplicar a uma seqüência discursiva, encadeando enunciados e estabelecendo relações textuais e discursivas entre eles.

\section{Onde aplicado à sentença}

O item onde é tradicionalmente analisado como um advérbio que se aplica à sentença, já que aparece em torno do núcleo verbal e exerce a função de adjunto adverbial. É, então, considerado pelas gramáticas do português padrão como advérbio que "indica o lugar em que se situa a ação verbal". É também analisado como pronome relativo (ou advérbio relativo) que eqüivale a em que, quando desempenha na sentença o papel de pronome, que se reporta a um nome, e ainda estabelece uma relação entre duas orações. Se consultarmos essas gramáticas, veremos que elas fazem a recomendação de que onde seja empregado com referência a lugar, estando seu antecedente expresso ou latente.

Em manuais de redação - como o da Folha de S. Paulo ou o do Estadão, por exemplo - em que se procuram apresentar instruções que possibilitem aos leitores a produção de textos "claros, objetivos e didáticos", vamos encontrar a observação de que o onde "eqüivale a em que apenas quando a referência é a lugar físico". Nesse caso, o seu uso em: "A tese onde ele defende essa idéia" é considerado um erro. Dessa forma tais manuais recomendam que, em exemplos desse tipo, seja usado sempre "em que, na qual ou no qual e não onde". ${ }^{3} \mathrm{O}$ uso do onde com referência a lugar físico, lugar

${ }^{3}$ Manual de Redação (Estadão) (www.estado.com.br/redac/geral.html) 
em que, é facilmente encontrado, nos textos pesquisados, como exemplifico com (1) a (3): ${ }^{4}$

(1) "Naquela época a sede da APUBH era na Faculdade de Filosofia, lugar onde se organizava o movimento." (TO)

(2) "Mandaram-nos para Cataguases, onde havia um grande pólo da Companhia." (TO)

(3) Depois que passamos pela floresta, chegamos em uma aldeia onde vivia uma tribo indígena. Eles não eram muito hostis e por isso permitiram que nós ficássemos lá a noite. (TE)

Nos exemplos (1) a (3) o item onde funciona como advérbio relativo, aplicado à sentença, que, como elemento anafórico, retoma os antecedentes "lugar", "Cataguases" e "aldeia", todos com idéia de lugar, e liga duas proposições que correspondem às orações que formam o período.

Agora, são também comuns exemplos de onde atuando como pronome relativo, mas retomando um antecedente sem referência a lugar físico. Examinando tais exemplos, pude perceber que os produtores dos textos que pesquisei o têm empregado também quando seu antecedente indica lugar nocional, evento, tempo ou mesmo posse.

Nos casos ilustrados em (4) a (6), onde faz referência ao que Kersch (1996) $)^{5}$ denomina de lugar abstrato, nocional, ou seja, que tem "uma noção de espaço abstrata, por ser apenas do domínio das idéias". Nesses exemplos onde estabelece referência a "história", "organismo", "coleção", etc.:

(4) Os textos retratam situações do dia-a-dia das crianças e não uma história onde existe aquele herói inatingível e invencível. (TE)

${ }^{4}$ (TO) está indicando que o exemplo foi extraído de gravações de textos orais (entrevistas ou debates) produzidos por professores da UFMG; e (TE) que foi extraído de textos escritos por alunos de Graduação da UFMG.

${ }^{5}$ KERSCH, 1996. *Não será citada a página em que se encontram as observações da autora porque a versão do seu trabalho que consultei está em disquete. 
(5) "...E com ele dividi a edição de Caminhos. O Conselho Editorial definiu que a Revista tinha que ser plural, e os artigos inéditos. Tentaríamos levantar temas e sugerir temáticas comuns. Caminhos não era, de maneira nenhuma um organismo oficial onde se publicassem determinados documentos, como acontecia às vezes com a revista da ANDES. Não era nada de oficial. Ela tinha que ser separada." (TO)

(6) MC é uma estilista formada em arquitetura e administração de empresas que apresentou sua primeira coleção onde une audácia e sobriedade. (TE)

A substituição do onde por em que, no qual ou na qual nesses casos tornaria tais seqüências aceitáveis pelos padrões estabelecidos pelas gramáticas. Mas é interessante observar que não foram essas as escolhas feitas pelos usuários da língua.

Ainda atuando como advérbio aplicado à sentença, retomando um antecedente que pertence ao segmento que o precede, encontram-se casos em que onde faz referência à noção de tempo. Embora, como mencionei anteriormente, haja na tradição gramatical recomendações expressas de que onde só se refira a lugar, o dicionário Aurélio, como observa Kersch (op.cit.), registra essa acepção temporal de onde, ao apresentar quando como seu sinônimo.

(7) O verso em Whitman, é feito de enumerações e paralelismos. Whitman inovou na poesia numa época onde tudo o mais já tinha mudado. (TE)

(8) A quarta ideologia surge no século XX, onde tem-se uma Universidade pluralista e massificada, com objetivo principal sendo o bem social. (TE)

(9) A entrevista foi reelaborada por nós, juntos, em frente a um dos computadores da APUBH. Foram sextas-feiras divertidíssimas, onde a vida do Professor foi literalmente passada a limpo! (TO)

Esse emprego do onde, embora inaceitável para os críticos dos usos que fazemos dos elementos da nossa língua, não deve ser considerado erro, pois, em português, existe uma dificuldade para 
separar espaço e tempo. Como nos mostra Pontes (1992), ${ }^{6}$ "indicamos tempo utilizando as categorias que indicam espaço". Segundo a autora, "nós concebemos o tempo como se ele fosse igual a espaço. Como tempo é um conceito abstrato, nós o tornamos mais concreto, nós o vemos como se fosse outra coisa, neste caso, espaço." Assim, "os elementos indicadores de lugar são usados para indicar tempo". O emprego de onde em casos como os de (7) a (9) evidencia que os usuários da língua tendem a projetar "distinções espaciais para falar do tempo". ${ }^{7}$

Encontram-se também, nos textos pesquisados, exemplos em que o onde parece surgir como alternativa ao emprego do pronome relativo cujo, já que estabeleceria entre os segmentos do texto uma relação de posse. Kersch (op. cit.) observa que o pronome cujo é hoje praticamente inexistente na fala e que a sua substituição por onde ocorreria, entre outros motivos, devido à escolha do falante de usar uma forma "mais popular para significar o que significa a forma mais erudita, menos usual".

(10) Temos um convênio com 215 a 220 creches comunitárias, que trabalham com crianças de 0 a 6 anos, onde os profissionais são totalmente desqualificados. Inclusive sem curso de ensino fundamental. (TO)

(11) Surpreendentemente, (devido a informações distorcidas), vamos identificar na Idade Média uma profusão de celebrações populares onde a tônica é o riso, a desconstrução mordaz do discurso oficial representado pela Igreja e pelo Estado. (TE)

(12) Um exemplo que pode ser ressaltado é a presença de expressões como "Outro ponto importante...". Desse modo, o autor consegue fazer uma redação onde a idéia central é desenvolvida sem a repetição de aspectos. (TE)

${ }^{6}$ PONTES, 1992, p.71 e p.75.

7 PONTES, 1992, p. 84. 
Nesses exemplos podemos interpretar que exista entre os elementos ligados pelo onde uma relação de posse, como se se quisesse expressar:

(13) Temos um convênio com 215 a 220 creches comunitárias, que trabalham com crianças de 0 a 6 anos, cujos profissionais são totalmente desqualificados. Inclusive sem curso de ensino fundamental.

(14) Surpreendentemente, (devido a informações distorcidas), vamos identificar na Idade Média uma profusão de celebrações populares cuja tônica é o riso, a desconstrução mordaz do discurso oficial representado pela Igreja e pelo Estado.

(15) Um exemplo que pode ser ressaltado é a presença de expressões como "Outro ponto importante...". Desse modo, o autor consegue fazer uma redação cuja idéia central é desenvolvida sem a repetição de aspectos.

Mas não se pode deixar de perceber que os referentes do onde desses exemplos, ou seja, os termos "creches comunitárias", "celebrações comunitárias" e "redação" trazem uma noção de espaço, físico ou nocional. Assim, com relação a esses exemplos, acho importante observar que interpreto o onde atuando tanto com referência a posse quanto com referência a lugar (físico ou nocional), e que talvez seja devido a essa sua dupla atuação - e não à recusa ao emprego de cujo - que os usuários do português tenham preferido empregá-lo.

\section{Onde aplicado ao discurso}

No item 2 foram apresentadas atuações do onde, em que ele se aplica à sentença, ao retomar uma palavra expressa anteriormente na estrutura sentencial. Neste item, pretendo apresentar outros usos em que ele parece ultrapassar os limites sentenciais. Nesses casos ele parece estar atuando como um conectivo textual, um articulador, responsável pelo estabelecimento da coesão textual, já que encadeia enunciados estabelecendo relações textuais e discursivas entre eles. 
O onde tem sido encontrado, tanto em manifestações orais quanto escritas, atuando como conectivo - responsável pela relação entre os enunciados de um período - e, ao mesmo tempo, como articulador discursivo - responsável pela inter-relação entre tópicos de um discurso.

3.1. Em alguns casos o onde parece estar atuando como um elemento anafórico, que retoma um referente, e ao mesmo tempo como um conector que aponta uma relação de explicação/ justificação, conseqüência ou relações de proporcionalidade e de mediação entre as proposições numa seqüência lingüística:

(16) A saúde no Brasil está deficitária, onde o governo não apóia os profissionais da área de saúde. (TE)

(17) Então, necessário se faz uma verdadeira revolução na metodologia de ensino da língua pátria, onde os educadores ao assumirem as rédeas de um movimento renovador do ensino, baseando-o em intensiva atividade de leitura e prática escrita, estariam direcionando a nação aos caminhos literários pertencentes à uma verdadeira democracia, pois somente um povo conhecedor de seus direitos é capaz de exercer os princípios legítimos da cidadania. (TE)

(18) Há um artesanato intelectual, onde as pessoas se sentem independentes na produção que fazem. (TO)

(19) A intertextualidade foi outro critério adotado, onde se pudesse observar em que medida o conhecimento ou não de outros textos interferiria na leitura. (TE)

(20) O texto O Homem e as Plantas é um texto mal estruturado, foi feito de uma forma não organizada, onde falta pontuação, vírgula, travessão, não possui autor, sendo então um texto com muitos problemas graves. (TE)

(21) A indústria brasileira, especificamente a mineira, atingiu determinado estágio onde, sem dúvida nenhuma, podemos ser considerados atores importantes no cenário do mercado mundial industrial. (TO)

Nesses exemplos, o onde parece atuar como item remissivo que retoma não uma palavra, mas uma idéia expressa no segmento 
que o precede - e, ao mesmo tempo, como conector, estabelecendo entre os segmentos dos enunciados relações semânticas e/ou pragmáticas. Assim, teria a propriedade de conectivo textual envolvido na estruturação do texto. Em casos como os de (16) a (21), ele seria denominado por Kersch (op. cit.) de "onde discursivo, o onde usado como elemento de coesão seqüencial, ou seja, usado para ligar orações, estabelecendo uma relação - possivelmente - de conclusão, com valor aproximado a de modo que, com o que, e assim". ${ }^{8}$ Acho importante salientar que, na presente análise, considero serem "estes ondes" elementos responsáveis não só pela coesão seqüencial, já que relacionam seqüências lingüisticas ou enunciados, mas ainda pela coesão referencial, já que também estabelecem referência.

3.2. Encontro outros exemplos em que o onde parece ter papel cumulativo, já que, como advérbio relativo, se refere a um antecedente e, como conectivo textual, atua na articulação da estruturação tópica do discurso. Como mostro em (22), onde apresenta uma nova direção à informação em curso na medida em que introduz novos tópicos e subtópicos (unidades discursivas semanticamente centradas):

(22) Sobre Movimento Docente e greve tive ocasião de escrever durante a mais longa greve que tivemos (124 dias) - a de 1991 - um longo artigo, publicado em Caminhos ( $\mathrm{n}^{\circ}$ 4) em que defendia a greve contra os opositores ao Movimento Docente e onde comunicava uma descoberta que tinha feito ao ler o estudo de J. Ben-David sobre a Universidade, qual seja, a de que, já no nascedouro da Universidade no século XII, seus fundadores (os professores e os alunos) tinham na greve uma prerrogativa e um direito de defesa da instituição. (TO)

${ }^{8}$ Segundo Kersch (1996a), foi Eneida R.M. Bonfim, em Variação e Mudança no Português Arcaico: o caso de $u$ e de onde, que adotou tal denominação "já que, por vezes, onde tem essa função de coesão, quer referencial, quer seqüencial”. 
Analisando esse exemplo, pode-se depreender, nessa seqüência lingüística, a seguinte organização tópica (diagrama 1): tem-se um tópico superior, mais abrangente, que engloba os outros tópicos, "greve", um quadro tópico, "originado das relações de interdependência entre os níveis hierárquicos de organização tópica", " artigo publicado em Caminhos", que é constituído pelos subtópicos, "tópicos co-constituintes situados numa mesma camada de organização tópica na medida em que apresentam o mesmo teor de concernência relativamente ao supertópico que lhes é comum", ${ }^{10}$ "defesa da greve contra os opositores do Movimento Docente" e "comunicação de uma descoberta feita ao ler o livro...", que podem se subdividir em segmentos tópicos, "subdivisões sucessivas no interior de cada tópico co-constituinte". ${ }^{11}$

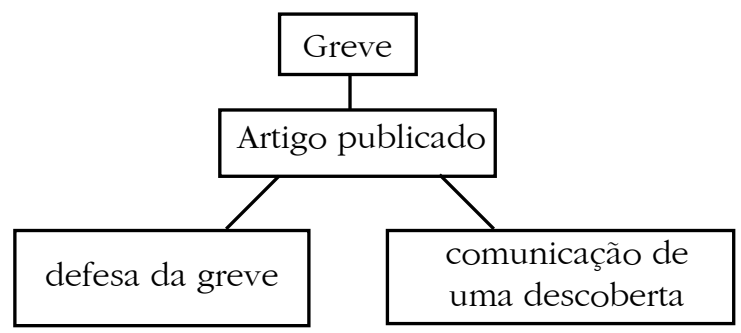

Diagrama (1)

Essa estruturação pode ser útil para mostrar que o onde, nesse trecho, pode estar funcionando como marca lingüístico-discursiva da orientação tópica do texto. De acordo com a interpretação que faço desse trecho, o onde aqui, ao mesmo tempo em que se refere ao antecedente "um longo artigo", está introduzindo um subtópico,

9 JUBRAN et alii, 1993. p.364.

${ }^{10}$ JUBRAN et alii, 1993.

${ }^{11}$ JUBRAN et alii, 1993. 
"comunicação de uma descoberta feita ao ler o livro...", que, de certa forma, muda a orientação dada pelo falante ao raciocínio que vinha desenvolvendo.

Outro exemplo ilustra também essa mudança de tópico ou de orientação do locutor no desenvolvimento da informação em curso:

(23) Então, dentro dessa política da universidade, de buscar, também, a interiorização e estreitar, cada vez mais, a relação com o ensino fundamental, temos um sub-programa, que é a educação para o trabalho, onde trabalhamos muito nessa perspectiva de questionar a educação apenas para o adestramento. É um trabalho muito interessante, porque são vários pontos de vista e há alguns questionamentos. (TO)

Nesse exemplo, onde retoma o termo "sub-programa" e, ainda, contribui para a inter-relação entre dois tópicos do discurso, "estreitar relação com o ensino fundamental" e "questionar a educação apenas para o adestramento".

São encontrados, ainda, exemplos em que o item onde aparece sem um referente, explícito ou latente, ou com um referente ambíguo, ou seja, que não é facilmente identificável no texto e por isso constitui uma dificuldade na sua compreensão. Nestes exemplos arrisco a dizer que ele tem por função estabelecer uma relação coesiva entre proposições, expressando o nexo entre os elementos do discurso, no âmbito de tópicos e segmentos de tópicos:

Outro ponto importante é a oportunidade do público participar do programa seja através de fax ou do diálogo dirêto; oportunidade criada pela produção e pelo próprio Jô Soares. Além disso cabe ressaltar a banda ou melhor o quinteto presente no show, onde além de tocar é presente em comentários, e alguns deles são os mais esdrúxulos, realizados em momentos do programa. (TE)

(24) Os problemas familiares acontecidos no seio do lar, como uma atenção excessiva ou repressiva dos pais, podem e devem ser resolvidos através de uma conversa sincera e honesta, onde a fuga e a busca de soluções paliativas certamente irão determinar um futuro sombrio e sem esperanças. (TE) 
Esses exemplos parecem evidenciar que o onde está mesmo atuando na articulação tópica do texto, na medida em que auxilia a inter-relação entre os tópicos dessas seqüências discursivas.

3.3. Em outros exemplos, encontro o onde atuando como um articulador entre tópicos, na condição de elemento não integrado à estrutura sintática da sentença, ou seja, ele é empregado pelos usuários da língua ainda que não tenha qualquer função sintática:

(26) Geralmente são três os entrevistados onde cada entrevista é separada pelo tempo comercial e ao final do programa há quase sempre uma apresentação musical. (TE)

(27) Todos nós somos programados para falar, temos uma propensão inata para a linguagem. Aprender a falar é uma evolução natural onde precisamos ouvir para selecionar nosso vocabulário. (TE)

Percebe-se, em (26) e (27), que o onde não está sintaticamente integrado à sentença a que pertence, tanto que dá a impressão de ser um elemento descartável de modo que sua exclusão, nesses casos, não prejudicaria a frase, numa perspectiva estritamente sintática. O seu uso nesses exemplos, então, parece reforçar a idéia de que o onde pode exercer (e exerce) a função de articulador discursivo, que contribui para a inter-relação entre tópicos.

\section{Conclusão}

Os usos diferenciados do onde nos textos pesquisados, como discuti através dos exemplos apresentados neste trabalho, apontam para uma ampliação no seu campo de atuação. Procurei mostrar que há casos em que o onde está atuando no âmbito do discurso, como articulador da organização tópica e não somente no âmbito da sentença, como advérbio relativo. Mostrei que ele, em diversos enunciados, não está funcionando apenas como elemento de delimitação ou restrição, o qual restringe a extensão de um termo (que faz referência a lugar ou não) que pertence à outra sentença função exercida pelo pronome relativo -, mas está atuando na 
estruturação tópica do texto, como elemento que faz o encadeamento dos enunciados, e estabelece relações textuais e discursivas entre eles.

Espero que, com esta análise preliminar, já possa ter mostrado que os usos que fazemos do item onde, embora condenados pelos que defendem a total (e cega) obediência às regras compendiadas nas gramáticas tradicionais do português, não devem ser condenados nem julgados como erro, mas sim cuidadosamente estudados, investigados para que se possa perceber sua atuação como marca lingüístico-discursiva da organização tópica do discurso.

\section{Referências Bibliográficas}

BASÍLIO, Margarida. As Abordagens e o Objeto de Estudo no Projeto Gramática do Português Falado. In: CASTILHO, Ataliba T. (Org.). Gramática do Português Falado. Vol III: As Abordagens. Campinas, SP: Ed. Da UNICAMP, São Paulo: FAPESP, 1993.

CASTILHO, Ataliba T. de. A lingua falada no ensino de português. São Paulo: Contexto, 1998.

COSTA VAL, Maria da Graça. Redação e textualidade. São Paulo: Martins Fontes, 1991.

FÁVERO, Leonor Lopes. Coesão e coerência textuais. São Paulo: Ática, 1991.

FULGÊNCIO, L. \& LIBERATO, Y. Como facilitar a leitura. São Paulo: Contexto, 1992.

JUBRAN et alii. Organização Tópica da Conversação. In: ILARI, R. Gramática do Português Falado. Vol. II: Niveis de Análise Lingüística. 2. ed. Campinas, SP: Editora da UNICAMP, 1993.

KERSCH, Dorotea Frank. A Palavra Onde no Português do Brasil.

Dissertação de Mestrado. Porto Alegre: UFRGS, 1996. 
KERSCH, Dorotea Frank. Onde - uma questão de lugar? In: LIMA, Marília dos Santos e GUEDES, Paulo Coimbra (Orgs). Estudos de Linguagem. Porto Alegre: Sagra - D.C. Luzzato (eds), 1996a.

KOCH \& TRAVAGLIA. Texto e coerência. 3. ed. São Paulo: Cortez, 1993.

KOCH, Ingedore G. Villaça. A coesão textual. São Paulo: Contexto, 1989.

KOCH, Ingedore G. Villaça. A inter-ação pela linguagem. São Paulo: Contexto, 1992.

KOCH, Ingedore G. Villaça. Dificuldades na leitura/produção de textos: Conectores interfrásticos. In: KIRST, Marta, CLEMENTE, Ivo (Orgs.). Lingüística aplicada ao ensino de português. Porto Alegre: Mercado Aberto, 1987a .

MARCUSCHI, Luiz Antônio. Da fala para a escrita: processos de retextualização. Recife: UFPE, 1995 (mimeo).

PONTES, Eunice. Espaço e tempo na Lingua Portuguesa. Campinas/ SP: Pontes, 1992.

RISSO, Mercedes S. "Agora... o que eu acho é o seguinte": um aspecto da articulação do discurso no português culto falado. In: CASTILHO, Ataliba T. (Org.). Gramática do Português Falado. Vol. III: As Abordagens. Campinas, SP: Ed. Da UNICAMP, São Paulo: FAPESP, 1993.

RISSO, Mercedes S. O Articulador discursivo "então". In: CASTILHO, Ataliba T. \& BASÍLIO, Margarida. (Orgs). Gramática do Português Falado. Vol IV: Estudos Descritivos. Campinas, SP: Ed. Da UNICAMP, São Paulo: FAPESP, 1996.

RODRIGUES, Andréa. Os níveis da atuação do Mas no discurso. Cadernos de Estudos Lingüísticos. Campinas, UNICAMP, n. 28, jan./jun. 1995.

VAN DIJK, Teun. Cognição, discurso e interação. São Paulo: Contexto, 1996. 


\section{Resumo}

Este trabalho pretende apresentar uma análise preliminar do uso de um mecanismo coesivo - o articulador onde - em textos orais e escritos, produzidos por alunos e professores universitários. Pretendo mostrar, através de exemplos extraídos de vários textos, diferentes usos desse mecanismo bem como discutir sua atuação tanto no âmbito da sentença quanto no âmbito do discurso.

\section{Abstract}

This paper presents a preliminary analysis of the use of the item onde (where) in oral and written texts produced by university students and professors. We intend to show, through several examples found in many texts, different uses of this coesive mechanism and also to discuss a possible enlargement of its field of action. 